\title{
Bolzanian knowing: infallibility, virtue and foundational truth
}

\author{
Anita Konzelmann Ziv
}

Received: 24 March 2008 / Accepted: 14 April 2009

(C) Springer Science+Business Media B.V. 2009

\begin{abstract}
The paper discusses Bernard Bolzano's epistemological approach to believing and knowing with regard to the epistemic requirements of an axiomatic model of science. It relates Bolzano's notions of believing, knowing and evaluation to notions of infallibility, immediacy and foundational truth. If axiomatic systems require their foundational truths to be infallibly known, this knowledge involves both evaluation of the infallibility of the asserted truth and evaluation of its being foundational. The twofold attempt to examine one's assertions and to do so by searching for the objective grounds of the truths asserted lies at the heart of Bolzano's notion of knowledge. However, the explanatory task of searching for grounds requires methods that cannot warrant infallibility. Hence, its constitutive role in a conception of knowledge seems to imply the fallibility of such knowledge. I argue that the explanatory task contained in Bolzanian knowing involves a high degree of epistemic virtues, and that it is only through some salient virtue that the credit of infallibility can distinguish Bolzanian knowing from a high degree of Bolzanian believing.
\end{abstract}

Keywords Believing - Knowing - Infallibility · Immediacy · Foundational truth · Epistemic evaluation · Explanation · Epistemic virtue

\section{Introduction}

My discussion of Bernard Bolzano's conception of knowledge and its relation to the epistemic requirements of an axiomatic system presupposes that Bolzano is a partisan of the traditional axiomatic model of science. ${ }^{1}$ Consequently, his epistemology is

${ }^{1}$ For details, see de Jong and Betti (2008) and Lapointe (2008).

A. Konzelmann Ziv ( $\varangle)$

Philosophisches Seminar, Universität Basel, Nadelberg 6-8, 4051 Basel, Switzerland

e-mail: anita.konzelmann@unibas.ch 
committed to the epistemic requirements of the model, summarized in the following principles: (a) all propositions in a system $S$ are known to be true (a non-fundamental proposition is known to be true through its proof in $S$ ), and (b) all concepts in $S$ are adequately known (a non-fundamental concept is adequately known through its composition or definition). ${ }^{2}$ For the present purpose, I will restrain considerations to the scope of principle (a) that embraces, on the one hand, rules of inference and the extent of their application, and, on the other hand, the epistemic status of axioms or foundational truths. ${ }^{3}$ The latter concern divides into the question of how to know axioms to be true and the question of how to know them to be foundational. Answers to these questions are often given in terms of impregnable or self-evident beliefs. Another option is to say that axioms are just stated. In this case, due to their hypothetical status no truth-value can be ascribed to them. Here, the question is for the epistemic status of hypotheses, as well as for assertions of the form " $[p]$ is a foundational truth in $S$ ". 4 If axioms are imported from the domain of another science, the question of foundational knowledge is reported to that domain. Then, foundational knowledge seems to be dependent on the coherence of scientific systems or on a hierarchy of scientific systems in which the question of foundation recurs.

Often, axiomatic models of science go together with foundationalist epistemological accounts that explain knowledge and justification in terms of foundational beliefs being "self-evident" or resulting from some special epistemic faculty-for example "intuition". The main objections to foundationalism query the lack of criteria for selfevidence, as well as the arbitrariness of intuitional faculties. Bolzano aligns with this criticism, opposing vehemently all claims for intuitional insight as justificatory of infallibility (Bolzano 1837a $\$ 315$, annotation). ${ }^{5}$ He supports, on the other hand, the idea of infallible knowledge resulting from "immediate judgments". 6 Yet, he equally admits a substantial lack of criteria for these latter. Therefore, his epistemology cannot be qualified as essentially foundationalist, in spite of some strong foundationalist claims with regard to the ultimate truths of all sciences. The best fitting contempo-

2 Following de Jong and Betti (2008).

3 "Given the difference between fundamental and non-fundamental elements, the Model has to accommodate two kinds of justification, one for the fundamental, and one for the non-fundamental elements. [...] Grounded knowledge is to be intended as knowledge propter quid or demonstrative knowledge [...]. Scientific knowledge according to the postulate of grounded knowledge is knowledge which is also explanative; in it the ordo cognoscendi matches the ordo essendi." (de Jong and Betti 2008).

4 I will use the following notations:

$[p]$ : for a proposition stating $p$

$[P]$ : for a collection of $[p]$

" $p$ ": for a subjective representation of $p$

" $p$ !": for a judgment (assertion) of $[p]$.

5 All quotes from Bolzano 1837a: author's translation.

6 The argument for this claim is typically foundationalist: "It is equally certain that there are also immediate judgments; for the existence of mediated ones can in the end be understood only because there are also immediate judgments" (Bolzano 1837b $\$ 300.3 ; c f . \$ 300.11$ ). For the claim of necessary trustworthiness of immediate judgments, Bolzano argues in terms of anti-skepticism: "But if you consider [...] possible [...] that one of your immediately formed judgments is false or that one of your immediate forms of inference is invalid, then you must distrust indeed not only some, but all your immediate judgments and forms of inference. For all of them have only one and the same warrant, namely your immediate consciousness. You [...] should therefore not form any judgments at all" (Bolzano 1837b §42). 
rary label for Bolzano's approach is Virtue Epistemology in its responsibilist version, which combines reliabilist concerns for epistemic success with internalist concerns for agentive responsibility for knowledge.

In the following, I shall first give an overview of Bolzano's use of central epistemological terms and then focus on the question of infallible knowledge. I will show how the claim for the existence of infallible assertions is related to the exhortation to test one's judgments. Bolzano characterizes such testing not primarily as an epistemic duty but, rather, as an act of epistemic nobleness essentially connected with the zeal to increase knowledge. The most important goal in increasing knowledge is explanatory; that is, to advance as far as to the objective grounds of an asserted truth. ${ }^{7}$ I will outline how these supreme epistemic values call for a legitimation of "inverted" ways to knowledge, as well as for an ineluctably virtue-based epistemic ethics.

\section{Epistemological notions}

In the introductory part of his seminal work Theory of science (Wissenschaftslehre), Bolzano connects science (Wissenschaft) with knowledge (Wissen) in the following words:

I therefore take the liberty to call an aggregate of truths of a certain kind a science [Wissenschaft], if what is known of it is important enough to be set forth in a special book. [...] For instance, I shall call the class of all truths which assert something about the constitution of space the science of space (geometry), because these propositions form a separate species of truths. (Bolzano $1837 \mathrm{~b} \$ 1.1)$

Bolzano formulates this "Domain Postulate" 8 not only in terms of a class of truths determined by a specific set of objects, but also in the pragmatic terms of its worth for a community of knowers. Apart from being a mere domain of objective truths, then, a science is moreover a domain of knowledge. Thus, the logic providing the rules to direct scientific (or more broadly epistemic) agency is a logic whose concept is close to that of epistemic logic. According to Nicholas Rescher, epistemic logic is "applied logic" which has to reflect the "ultimately factual circumstances" of intelligent beings' cognitive situation. Therefore, the theses of such a logical system are considered to "stand correlative to the ways in which we actually do talk and think about the matter". 9

While the term "knowledge" in the expression "domain of knowledge" is unspecified, meaning roughly "correct assertions supported in an acceptable way", the same term will be given a specific meaning in epistemological considerations. In Bolzano's epistemology (Erkenntnistheorie), however, "knowing" is not the central term. Rather, it is an epistemology centered on the notions of "judgment" (Urteil) and "cognition" (Erkenntnis)—corresponding to the contemporary labels "belief" and "true belief"-

\footnotetext{
7 For Bolzano's theory of grounding see Tatzel (2002) and Lapointe (2008).

8 On the Domain Postulate see the introduction and de Jong and Betti (2008).

9 Rescher (2005, p. 5).
} 
as well as on the notion of "inference" (Schliessen). The primary epistemic act is judging, that is "taking for true" (asserting) a certain objective proposition. Judging can be either "immediate" or "mediated" by inference. In Bolzano's view, believing (Glauben) and knowing (Wissen) are secondary to judging in that they name reflective attitudes of epistemic agents towards their judgments (Bolzano 1837a §321). Believing and knowing are introduced as attitudes resulting from assessing the fallibility of judgments. While an immediate judgment is supposed to have fallibility 0 - default infallibility - the fallibility of inferred judgments depends on the way they are inferred. If the inference is "perfect deduction", that is, starts from correct assertions and follows deductive rules properly, the resulting judgment is infallible. If, on the other hand, there is uncertainty as to the correctness of premises asserted or rule following, the inferred judgment is fallible. ${ }^{10}$ Consequently, the reflective attitude towards such a judgment is Bolzanian believing, while Bolzanian knowing reflects the assessment of one's judgment as infallible.

It follows from the foregoing that Bolzano's specified concept of knowledge is internalist: an analysis of "A knows that p" essentially involves agent A's subjective appraisal of her judgmental activity. Bolzano seems to take it for granted that epistemic agents have a kind of primitive self-attitude towards their cognitive processes, similarly to what Keith Lehrer labels as "self-trust", ${ }^{11}$ and that this attitude, if reflected, is manifested in knowing and believing. On the other hand, Bolzano assumes that judgmental activity naturally runs in the direction of its intrinsic aim of asserting truth. This "teleological reliabilism" is based in his metaphysics of the mind that links the causality of mental processes with the necessity of logical laws. With regard to the ontological status of the mind, Bolzano defends a substance monism, according to which a mind or "soul" is the "ruling substance" within an "organic" aggregate of substances, called a "body". ${ }^{12}$ Since substances are defined as self-sustaining efficacious simples and are efficacious in virtue of having causal "forces", this position suggests that the activity of the mind is to be accounted for in causal terms. Given such an account, the activity of a mental substance consists in its running causal processes that are governed by the laws of mental forces. These processes are taken to be reliable ways to achieve the epistemic aim of judgments' truth-conformity. Bolzano emphasizes the reliability of causal cognitive processes by linking causal and logical necessity in his notion of the ground-consequence relation (Abfolge), for which statements on causal relations count as paradigmatic instantiations. The strong emphasis on a causalist account of the properties of mental substances, together with the teleological claim that these properties unfold in processes that are truth-aimed, results in the reliabilist optimism that epistemic processes achieve their aim of truth-conformity if they function properly in appropriate circumstances. In Bolzano's epistemology, this externalist feature of process reliabilism meshes with the internalist feature of reflective assessment of one's epistemic procedures. The meshing becomes salient in

\footnotetext{
10 Bolzano defines doubt in terms of degrees of probability of confidence, and confidence as indicating either immediacy of judgment or the truth-probability of a proposition $[q]$ in relation to a set of premises.

11 "The first step in the life of reason is self-trust. I trust myself in what I accept and prefer, and I consider myself worthy of my trust in what I accept or prefer" (Lehrer 1997, p. 5).

12 See, for example, Berg (1976); Chisholm (1991); Krause (2004).
} 
terms such as "judgmental force", "representational force", "imaginative force" and so on. Here, the intentionalist vocabulary-traditionally used to account for subjectively accessible and manageable activities_combines with the reliabilist vocabulary of processual occurrence. Accordingly, epistemological notions such as "judging" are accounted for both in intentionalist terms (asserting the truth of an objective proposition), and in functionalist terms of subliminal processes that concatenate more or less strong "ideas" into a propositionally structured entity of thought.

Although internal epistemic processes run mostly unnoticed, they are not immune to beneficial or malefic influence. Epistemic practice shapes them in various ways, just as aesthetic and moral practice sharpen or weaken the faculties upon which they rely. Insofar, Bolzano's process reliabilism concerning judgmental activity is balanced by strong responsibilist claims concerning epistemic agency. The endeavor of epistemic performance is presented as a dimension of essentially ethical concern, determined not only in normative terms like "ought", "allowed" or "forbidden", but also in moral terms like "illicit" or "immoral" that emphasize epistemic responsibility (Bolzano 1837b $\S 317.3){ }^{13}$ If, for example, circumstances and indices for truth-conformity make it illicit not to accept a thought as cognition, the resulting conviction should correctly be called an "ethical, or moral, or sufficient" certainty (ibid.). This attitude corresponds to a large extent to ideas of virtue epistemology that attempt to amend the consequentialism of reliabilist accounts by adding the aspect of agentive responsibility to analyses of knowledge (see, for example, the work of J. Greco, L. Zagzebski, C. Hookway).

An example of a virtue epistemological approach to knowledge is Linda Zagzebski's argument that the reliability of a process cannot confer any added value to its result, since the process receives its own value from the fact that it leads to the given result. So if knowledge shall be more valuable than reliably true belief, the additional value cannot be explained in terms of the reliability of the process leading to it. The explanation must, instead, refer to motivational attitudes that initiate and sustain the actions and processes leading to true belief. ${ }^{14}$ Similarly, Bolzano's Theory of science emphasizes the responsibility of epistemic agents to make sure that their practices meet the high standards of epistemic ethics. For example, the scenario of epistemically irresponsible agents whose epistemic failings are constantly adjusted by a reliable demon Verity into the full success of exclusively true beliefs would not fit the conception of Bolzanian knowing. ${ }^{15}$ To be valuable, a concept of knowledge needs to relate notions of subjective responsibility in the search for truth with notions of success in reaching this aim. In the following, I will relate this point to what Bolzano says on the responsibility of testing one's judgments and explaining the truths asserted in them. I try to show, on the one hand, that the norms for these activities are aretaic rather than deontic

13 "If the absolute probability of a proposition for a certain being is very large and if there are circumstances which make it foolish or illicit to consider the possibility of the opposite and to act on it, then I call these propositions trustworthy, secure, reliable" (Bolzano 1837b §317.3).

14 Zagzebski (2000) account of knowledge can be expressed in the following scheme:

$S$ knows that $p$ iff

(i) $S$ has a "motive for truth", \&

(ii) $S$ behaves in a cognitively reliable manner because of (i), \&

(iii) $S$ successfully reaches the true belief that $p$ because of (ii).

15 See Swank (2000). 
in nature and, on the other hand, that they must account for the epistemic requirements of axiomatic systems.

\section{Infallibility and immediacy of judgment}

Let us now come back to the aforementioned attitudes of Bolzanian believing and knowing that reflect one's appraisal of one's judgment as either fallible or infallible. I take it that these evaluative attitudes have to be construed in terms of non-assertive thoughts, which, although cognitive in nature (conceptual or even propositional) may involve feelings and intentions as components. Compare, for example, the notion of "self-trust" mentioned above. A construal of believing and knowing in terms of higherorder judgments—agent A's judgment " $r$ !" assesses A's judgment " $q$ !" by asserting the latter's certainty or degree of subjective probability ${ }^{16}$ _induces an undesirable infinite regress. ${ }^{17}$ In order to avoid such evaluator regress, Bolzanian believing and knowing are to be explained as normative attitudes whose analyses refer to a broader realm of mental states than those usually treated as epistemically relevant. As a first approach, they can be analyzed in the following way (Bolzano 1837a §321):

(1) A knows $\mathrm{B}$ that $[q]$ iff A asserts $[q]$ \& A truly evaluates her asserting $[q]$ as infallible.

(2) A believes ${ }_{\mathrm{B}}$ that $[q]$ iff A asserts $[q] \&$ A evaluates her asserting $[q]$ as fallible.

The analysis of "knowing" does not need to mention the traditional clause of $[q]$ 's being true, since infallibility of assertion implies truth-conformity. The analysis' critical point lies in the correct evaluation of infallibility. If this evaluation is not itself infallible and A can be wrong about it, subjective and objective attribution of knowledge cannot be reconciled. In the analysis of "believing", however, a wrong evaluation of fallibility does not make a significant difference, since fallibility and truth-conformity are not related in the same way. If A evaluates " $q$ !" as fallible on the basis of $[q]$ 's probability $\mathrm{P}<1$, this evaluation allows for $[q]$ 's being true, and hence for A's judgment " $q$ !" to conform to truth. Bolzanian believing can be described as loyalty to a judgment " $q$ !", as a "relation of our ethos (Gesinnung)" to the truth of $[q]$, in spite of there being reasons against it (Bolzano 1837a §321). Believing is intimately connected to the virtue of trust that presupposes an agent's acknowledging the risk of

\footnotetext{
16 "Certainty" (Gewissheit) and "Confidence" (Zuversicht) are notions that qualify judgments in function of the deducibility or probability of objective propositions. Roughly, confidence with regard to a judgment " $q$ !" is the subjective probability of the judgment's conforming to truth (Bolzano 1837a $\S \S 317-320$ ). For the notions of deducibility and probability see Sect. 4.

17 For a similar idea see John Greco's remarks on subjective justification (S's believing $\mathrm{p}$ is the result of dispositions that $\mathrm{S}$ manifests when $\mathrm{S}$ is trying to believe the truth): "The knower must have some awareness that a belief so formed has a good likelihood of being true. Some authors have required that the knower believe that this is so, but [...] it seems that people rarely have beliefs about the genesis of their beliefs, and so it would be too strong to require that they always have one in cases of knowledge. [...] People manifest highly specific, finely tuned dispositions to form beliefs in some ways rather than others. And this fact, I take it, amounts to an implicit awareness of the reliability of those dispositions." (Greco 2003, p. 127f) To be noted: the term "belief" in Greco's use corresponds to the term "judgment" in Bolzano's use, not to Bolzanian believing.
} 
being deceived. ${ }^{18}$ Based on an evaluation that reveals good reasons and due attention to counterarguments, believing will not be disavowed in a significant way. If " $q$ !" has a high degree of "confidence", the chance of it not conforming to truth may be so low that it would be epistemically "vicious" not to behave as if $[q]$ were true. Believing is, on the other hand, also connected to the virtue of prudence that dissuades one from holding onto a judgment that has too many reasons against it. Believing is at home in the interplay of trust and prudence.

Similar considerations apply, although in a different manner, to Bolzanian knowing. While Bolzano assumes that infallibility is a default property of immediate, that is, non-inferential, judgments, he equally assumes that there are no definite criteria to distinguish immediate judgments from "unconsciously inferred" judgments. Since both are experienced as immediate, the virtuous epistemic agent will not lightheartedly evaluate an experience of immediacy as an indicator of infallibility. Contrary to those philosophers who pretend to "immediately cognize all the truths that they, each one in his system, establish" (Bolzano 1837a §315), she will not take experienced immediacy as unconditional justification for dogmatic claims. With regard to experienced immediacy, the salient virtue is prudence. Prudence does not exclude trust or amount to mistrust, but frames trust with a caveat. Testing a judgment even if it seems immediate is motivated mainly by the desire to bring the grounds of the asserted truth to full awareness, not by one's doubting the judgment. Although Bolzano suggests that there are globally foundational truths, that is, truths that do not have any objective grounds, he desists from trying to list such truths. ${ }^{19}$

Our judgments, even truly immediate—hence infallible—judgments, generally assert grounded truths. So even if there is no epistemic duty to justify a judgment by providing its reasons, there are epistemic virtues motivating the search for the grounds of the asserted truth. Bolzano emphasizes that this kind of investigating is a "business that we can undertake even then when we do not doubt the truth of the proposition in the least" (Bolzano 1837a \$332.8). His "Heuristics" in the Theory of science (Bolzano 1837a $\S \S 322-391$ ) is a strong plea for this point.

It is apposite to mention at this point that the concepts of Bolzanian believing and knowing do not imply continuous reflective appraisal of one's judgments. The big part of epistemic activity runs without being accompanied by reflective awareness and is nevertheless able to compensate for errors. Insofar, Bolzano's epistemology draws importantly on ideas that nowadays are labeled as "Naturalized Rationality", postulating reasoning processes that are reliable, fast and frugalenough for the demands of a normal human life. As current research programs suggest, simple heuristics such as recognition, take-the-best and take-the-last prove "remarkably successful" and "perform almost as well as a bunch of fancier processing algorithms", while being much more frugal in the use of information and the demands placed on the computational

\footnotetext{
18 See for example Baier (1992).

19 Compare Sebestik (1992, p. 282): "It is paradoxal that Bolzano who renews the conception of the axiomatic does not establish in his Grössenlehre any proposition declared expressly as primitive truth or principle. Bolzano does not propose any list of axioms" (my translation).
} 
resources of a system. ${ }^{20}$ For many epistemic purposes, such minimal heuristics are sufficient.

Yet for more specific epistemic purpose such as establishing the foundational structure of a scientific system, appropriate heuristics demand that a selection of the assertions to be thoroughly checked is made. Even assertions of "self-evident" propositions considered to provide the foundational truths of a system merit investigation. Self-evidence might manifest in immediacy of judgment—-but due to the phenomenal indistinguishability of immediate judgments and those achieved through unconscious (fallible) inference one should be careful about experienced immediacy. Having chosen to test an assertion, epistemic agents "ascend" a hierarchical order of grounds-Bolzano's Abfolge - towards the most general principles that can explain the asserted truth (Bolzano 1837a §220). The pathway followed may furcate repeatedly and lead to different possible explanations. Aside from the logical and semantic relations involved, it is the circumstances of investigation and the attitudes of the agents that determine the choices of ways and the extent of investigation in the course of their ascent. Whether an investigation has achieved the ultimate grounds is not easy to decide. Choosing "to abandon our testing and rightly so" at a given point springs from a pragmatic attitude involving many epistemic virtues that evaluate the results achieved so far, the resources available and the benefits and costs of further research (Bolzano 1837a §332.3).

Our initial question was whether the requirement of knowing the foundational principles of a system $\mathrm{S}$ can be accommodated within the frame of Bolzanian knowing. Applying the analysis of Bolzanian knowing to the epistemic requirement of axiomatic systems, we get the following form:

(3) A knows $s_{B}$ that $[p]$ is a foundational truth in $S$ iff A asserts that $[p]$ is a foundational truth in $S \&$ A truly evaluates her asserting so as infallible.

Bolzanian knowledge claims apply only to assertions. Since hypothesis is distinct from assertion, Bolzanian knowing cannot be claimed for the hypothesized axioms of a system conceived in hypothetico-deductive terms. Furthermore, it cannot be claimed for " $[p]$ is a foundational truth in $S$ ". Suppose that heuristic rules lead us "up" from some acknowledged truths $[Q]$ to more basic truths they derive from. The method is hypothetical or conditional in nature: we consider from what relevant set of truths $[P]$ our initial truths $[Q]$ can be inferred. No assertion of any $[p]$ is needed in order to evaluate whether $[P]$ entails $[Q]$. But plausibly, once the cogency of $[P]$ 's entailing $[Q]$ is established, we are inclined to assert the propositions in $[P]$ in their right as axioms of our system, and hence to assert a proposition of the form " $[p]$ is a foundational truth in $S$ ". Such an assertion, however, does not seem to be entailed by logical necessity. We can abstain from it, considering the propositions in $[P]$ as axioms of our system in a hypothetical mode. Doing so, we leave open the possibility of more appropriate axioms being found. If we assert the propositions in $[P]$ to be the axioms of $S$, this assertion can result in two ways: either it ensues from probabilistic inference, or it is a decisional "leap". In the first case, our epistemic attitude is just a variety of Bolzanian believing whose underlying evaluation revealed a high degree of probability. In the second case, the epistemic attitude seems to differ from believing since the awareness

20 Carruthers (2006). 
of potential error implied in believing is simply set at nought. If infallibility is to be preserved in Bolzanian knowing, it implies taking a decisional leap. Taking such a leap is epistemically daring: it is motivated rather by audaciousness than by trust and prudence.

As mentioned before, evaluating one's own assertion as infallible is the critical clause in the analysis of Bolzanian knowing. So far I have mentioned three features with regard to this problem. First, it seems that infallibility evaluation cannot itself be assertive, but rather has the character of a thought in the unspecified sense of a structured complex of concepts. ${ }^{21}$ Second, immediacy of judgment is not a sufficient condition for infallibility, since unconsciously inferred judgments appear equally immediate to the judging agent. Thus, in the case of apparently immediate judgment, the task of infallibility evaluation amounts to the evaluation of authentic immediacy. Third, perfect deduction that warrants a conclusion's infallibility is dependent on infallibility claims concerning its premises. Unless not all antecedent judgments have probability 1 - and hence infallibility — deductive inference will not be perfect, even if the argument is valid. Thus, evaluation of an inference's infallibility amounts to evaluation of the infallibility of its premises, and we are either in a regress or thrown back to the problem of evaluating immediacy. In view of this situation, the choice is between rejecting the infallibility claim categorically or attempting to save it by providing an account of immediacy evaluation. I will adopt the latter option.

\section{Immediacy evaluation}

The question of immediacy evaluation leads back to reliabilist considerations. For Bolzano, judging is the mental activity of asserting an objective proposition. Yet in order to assert an objective proposition $[q]$, an agent A does not simply "grasp" the ready-made proposition $[q]$ from the objective realm of propositions and adds her approval to it. Rather, A's asserting $[q]$ is considered the result of processes that involve various constructive mental "forces". Although the big part of A's constructive activity runs unnoticed, this is no reason to distrust its results. ${ }^{22}$ According to Bolzano, the cognitive process leading to a judgment is governed by what he calls the "judgmental force" (Urteilskraft), a force that concatenates a number of mental representations into propositionally structured complexes in a way that enforces approbation. Since Bolzano holds that all mental representations-whether simple or complex-mirror objective representations, there is no propositionally structured subjective representation that does not mirror an objective proposition. Therefore, what is "taken for true" or approved in judging is justly said to be the objective proposition $[q]$ providing the

\footnotetext{
21 "I feel the truth of p" refers to an evaluative attitude whose comprehended thought is conceptually complex but not necessarily propositionally structured. Even paraphrasing "I feel the truth of p" by "I feel that $\mathrm{p}$ is true" does not amount to claiming that the content of the feeling is a judgment, viz. assertive and in need of justification.

22 Bolzano thinks that the processes resulting in complex representations and judgments are "much more easily comprehended" when we assume "that in doing this the mind [Seele] does not form the judgment that it does it, but that it performs these operations without being clearly conscious of them" (Bolzano 1837b $\S 302.1)$.
} 
"matter" of the subjectively built representation " $q$ ". Operations of the "judgmental force" may or may not go together with operations of the "force of inference". In the first case, the judgment produced presupposes the "presence" of other judgments in the mind which then are "the complete cause for the occurrence" of " $q$ !" (Bolzano $1837 \mathrm{~b} \$ 300.2$ ). Here, approbation of $[q]$ is mediated by the mind's "moving" from these antecedent judgments to judgment " $q$ !". In the second case, a judgment " $q$ !" is "immediate" in that the approbation of $[q]$ is independent of inferential moves. Agent A's non-conceptual judgment "I feel a pain just now", for example, might gain its immediate approbation from the fact that it expresses an actually experienced physical state of A. For purely conceptual judgments, Bolzano claims that the compulsion for immediate approbation bears exclusively on the meaning of the concepts from which they are built and the relations between them: ${ }^{23}$

To the full reason why we couch our judgment in just that way, why we claim that each object represented by the concept $A$ has the property represented by the concept $b[\ldots]$ belongs primarily also the peculiar property of both the concepts $A$ and $b$ themselves. [...] it is obvious that - in order to explain the appearance of such a judgment in our mind (Gemüt) —we must not mention anything else [...] than that we envisage by $A$ and $b$ just those concepts that we really envisage (vorstellen) (Bolzano 1837a §302). ${ }^{24}$

Claims for infallibility of this kind of judgments draw on the semantic properties of the representations involved to produce immediate assertion. Bolzano does not distinguish subjective from objective representations by declaring the latter as "sense" or "meaning" of the former. Rather, the distinction is expressed in terms of the "real existence" of mental phenomena-adhering to individual subjects and having causal efficacy - that instantiate or exemplify a "certain something" which "subsists" and constitutes their "immediate matter (Stoff)" (Bolzano 1837b §48.3). ${ }^{25}$ The semantics of representations is determined by their "content", which is the "sum of the components" a representation consists of, and the order of these components (Bolzano 1837b $\S 56)$. In general, a subjective representation " $F$ " and its objective matter $[F]$ do have the same content which enables them to fulfill their task of representing their common object (Bolzano 1837a §49.1). Agent A’s "having" a representation " $F$ " is a mental instance of $[F]$ that mirrors the semantic morphology of $[F]$ and goes together with the understanding of "expressions" or "signs" that "signify" $[F]$ (Bolzano 1837a §§79.2). If A has a propositionally structured conceptual representation " $q$ ", A apprehends

\footnotetext{
23 In Bolzano, a concept (Begriff) is a representation which is not an intuition (Anschauung) and does not contain any intuition. An intuition is defined as a semantically simple representation of a singular object, paradigmatically instantiated in the demonstrative [this]. A non-conceptual judgement is a judgment containing intuitions, a (purely) conceptual judgment does not contain intuitions.

24 "[W]hether we make a judgment or not [...] is a result [...] merely of the sum total of the ideas immediately present in our souls, according to a certain law of necessity" (Bolzano 1837c §291.5).

25 Bolzano uses the term "sense" or "meaning" (Sinn) with the complement noun "expression" or "sign", not with the complement noun "representation". Although in one place he qualifies an objective proposition as a "meaning", he does not qualify it as the meaning of a subjective representation but as the meaning of a "linguistic expression" (Bolzano 1839, §2.1; Bolzano 1837a §285). The notion of subjective representation is wider than that of linguistic expression.
} 
$[q]$ and understands linguistic signs signifying $[q]$. According to Bolzano's claim, the compulsion for immediate approbation is triggered in this case by A's having understandingly ordered a number of components into a complex, so that-under given epistemic circumstances - this ordered semantic complex manifests in the assertion " $A$ is $b$ !". It is also possible, though, that an identical judgment " $A$ is $b$ !" is mediated by conscious or unconscious inference. The class of judgments that are absolutely non-inferable by virtue of their semantic properties, i.e. their content,, is apparently empty. This fact makes it impossible to provide a structural feature to distinguish immediate judgments. Together with the fact of process opacity in the generation of judgments it rules out the possibility of absolute evaluation of infallibility.

As an anti-intuitionist conception of knowing that involves reflective evaluation of one's own epistemic performance, Bolzanian knowing seems restricted to approximate evaluation of infallibility. ${ }^{26}$ To maximize evaluation success, an agent needs to combine her skills in following acquired rules of testing with virtues motivating her choices as to the limits of such testing. Maximizing evaluation success also requires submitting the results for evaluation by others. Bolzano depicts a subjectivist epistemology, yet it is not individualist in the sense that it describes epistemic agency as a monadic activity. Epistemic agents are part of epistemic communities whose standards they adapt. Epistemic processes are not restricted to cognitive processes running in natural individuals, but also include collective processes of collecting, selecting, assimilating and distributing information. Bolzano factors this collective dimension into his epistemology by strong references to "common sense" that manifests, for example, in consensus and in the use of a common semiotic system in tracking truth. Bolzanian knowing seems to rely on an evaluation of infallibility that consists in the maximal combination of individual and collective abilities.

Yet if Bolzanian knowing relies on mere approximate evaluation of infallibility, then it seems to be just a higher level or an ideal case of Bolzanian believing and its evaluation of fallibility. If infallibility cannot be tracked in an absolute way, there is no point in making such tracking the definitional criterion of knowing. An attempt to save knowing as different from believing apparently requires an additional criterion that provides the value of the absolute. As briefly outlined, I think that such a criterion can be found in the difference between salient virtues involved in believing and knowing. Before tackling this topic again, I should like to present some features of Bolzanian heuristics that combine the responsibility of testing one's judgments with the task of searching the grounds of the truths asserted. This twofold task lies at the heart of both the evaluation of fallibility in believing and the evaluation of infallibility in knowing. Based on these heuristic requirements, the difference between salient virtues involved in believing and knowing will appear more articulate.

\footnotetext{
26 I use the term "anti-intuitionist" in the broad sense of denoting an epistemological position that defies the existence of a specific "intuitive" epistemic faculty allowing direct insight into the truth of a proposition. In Bolzano 1837a $\$ 315$ (annotation) Bolzano criticizes the intuitionist position, especially if it is used to dogmatically establish one's philosophical system. (This meaning of the term "intuition" differs from the one referred to in note 23. The English word "intuition" translates both the German "Anschauung" (a type of representation) and the German "Intuition" (an epistemic faculty)).
} 


\section{Heuristics and virtue}

The heuristics of searching the grounds of asserted truths presupposes a testing of judgments that is not motivated by doubts in the judgment or requests for justification but by a desire to reveal the objective grounds of the truth upon which a judgment bears. Love of truth and zeal to explain are considered to be the driving attitudes in epistemic and more specific scientific activity. ${ }^{27}$ Bolzano's heuristics is, as his entire epistemology, deeply rooted in ethical concerns, which are much more aretaic in nature than consequentialist or deontic. Within heuristics, it is primarily inductive and abductive reasoning that are within the scope of epistemic virtues. Contrary to rule-governed deductive reasoning, which is strictly valid or invalid and, as such, relatively insensitive to ethical concern, both inductive and abductive reasoning require that various factors be pondered and integrated in optimal ways into epistemic decisions. "Ascending to the grounds" of a given $[q]$ is striving for its best explanation among possible competing options. It requires abilities such as inventive talent, delight in exploration, patience, perseverance, humility and so on that reach beyond the steadiness of rule applying. Drawing on the results of abductive and inductive procedures, Bolzanian knowing is highly dependent on the efficiency of epistemic virtues.

The fact that Bolzano dissuades us from taking any apparent immediacy as a guarantee of infallibility abrogates the principle that knowing is attributable on the basis of subjective immediacy of foundational judgments. Whether a truth is foundational cannot be decided by immediacy of judgment, but can only be decided by working out abductive procedures. The results of abductive procedures, the first (or last) grounds, involve various decisions made on the way ascending to these grounds. These decisions are, consequently, part of Bolzanian knowing of foundational truth. They include, for example, decisions on where to stop investigations in order not to give them disproportional weight (Bolzano 1837a §332.3). Appropriate decisions require evaluative agentive properties, comparable to those by which artists apply the appropriate brushstroke or fit in the right word, or those by which wise people are aware of where to initiate or to stop certain actions. The moment to intervene in children's strife, for example, is not determinable by consulting a deontic precept. Rather, it requires the application of a wide range of skills and experience, as well as the virtues of wisdom, understanding, foresight, fairness and so on. Situations like that are characterized by their involvement of different and contradicting values. Virtues are those properties that can assess the diversity of values involved in a situation, working out cognitively and emotionally balanced responses to it. In the epistemic case, a virtuous approach works out a balanced response to the values of good reasons, the force of evidence, the strength of counterarguments, the relevance of contextual aspects and so on.

An aretaic approach to knowledge does not deny the necessity of mandatory precepts in the pursuit of truth. Rather, it emphasizes that the primary accent of the normative dimension in epistemological concerns is not the deontic character of rulefollowing, but the fact that epistemic duties warrant the success of epistemic activity when they are based in virtues. Bolzano's heuristics demonstrates how duty and virtue

27 Valuable "cogitation" (Nachdenken) is “directed to truth” or "searching for truth" (Bolzano 1837a §322). 
enlace in epistemic attempts: it provides, on the one hand, a collection of rules for one's "behavior in thinking", a "directive for thinking" which "ought to be observed" to successfully increase knowledge, and, on the other hand, explicitly resumes aspects of cogitation that are subject to what an agent "earnestly wants", and hence to the ethics of believing (Bolzano 1837a $\S \S 322,324$ ). The heart of Bolzano’s heuristics consists in a body of "general rules", among which the following three deserve specific attention in the present context: "Tentative supposition or indirect method" (rule no. 5, §329), "Consulting judgments of others and experience" (rule no. 7, §331), "Testing one”s own judgments" (rule no. 8, §332).

Heuristic rule no. 5 resumes the hypothetical method that "attempts to find truth by means of something that is not yet known to be true" (Bolzano 1837a §329.1). It combines with rule no. 8-testing one's judgments - to achieve the twofold goal of testing a seemingly immediate judgment by ascending to the grounds of the asserted truth. Bolzano admits that due to the involvement of the unknown in the procedure of knowing, the hypothetical method seems "artificial", "inverted" or "indirect" compared to the "natural" method of inferring known truth from known truth. Practicing exclusively the "natural" method of deduction-which presupposes assertion of grounds before assertion of consequences - restricts, however, knowledge extension in an unhealthy manner. People stubbornly insisting on deductive knowing as the only appropriate kind of knowing might appear stupid since all their cogitating may happen to lead to no significant result. On the other hand, the "inverted" methods are "amiss" in that they involve "haphazardness" and the favors of "serendipity" - and hence fallibility (Bolzano 1837a §330). Bolzano suggests that only a combination of "natural" and "inverted" methods allows accounting for knowing, and that the art of combining them ideally is highly determined by virtues.

Ascending to the "first grounds" of a set of truths requires the application of the hypothetical method that cannot rule out fallibility; nevertheless, faultiness is minimized if we choose our tentative suppositions "with proper skillfulness" and "perform the examination in all ways available to us" (Bolzano 1837a §329.2). The required skillfulness enables agents to select those propositions that are potentially expedient as hypothetical grounds for a given statement. "Proper skills" for this task evaluate the propositions' probability, their simplicity or their convenience for experiments with regard to the statement to be founded and the circumstances of investigation. Within the set of selected propositions, they can further establish a hierarchy that determines the sequence of examination (Bolzano 1837a \$329.3). The soundness of the potential explanans can be examined progressively by checking the truth-values of propositions entailed by it, or again regressively by applying the hypothetical method to the hypothetical grounds themselves. For general statements, induction is another appropriate method of examination that implies various epistemic and experiential skills (Bolzano 1837a §329.8). Sometimes, so Bolzano claims, it may even suffice to "think" the proposition to be examined "as clearly as possible", including representing it "in words or signs of another kind". This may lead us to "see" its evidence or to remember other occasions when we already considered its truth or falsity. While choosing the appropriate combination of these methods in the circumstances belongs to epistemic skillfulness, epistemic virtue requires us "not to take a proposition for true just because it pops up in our mind or appears there very vividly" (Bolzano 1837a §329.4). Bolzano 
does not exclude subjective evidence as a relevant factor for truth-conduciveness, but he shows that epistemically virtuous agents will not unconditionally rely upon it.

To help us to decide which combination of methods is the most promising in searching the grounds of a given truth, Bolzano suggests some pragmatic rules or principles. They are inspired, on the one hand, by the strong probabilistic nature of his logic and semantics, and, on the other hand, by consequentialist values. One such rule states that judgments must be tested only in cases in which "we see that a test is possible without assuming propositions that have less reliability than they have themselves". If the latter is the case, we could at best corroborate the tested judgment but not refute it. Hence, if its eligible reasons are only less reliable propositions, we can "confidently desist from such testing" (Bolzano 1837a \$332.7). It is obvious that the "reasons" mentioned here are supposed to refer to the objective grounds of the proposition $[q]$ asserted in " $q$ !", and not merely to its "epistemic reasons" that factually led us to assert " $q$ !". The reliability of propositions can be accounted for in terms of their relational property of probability. Contrary to a proposition's intrinsic truth or falsity, a proposition's probability is a relational property depending on a certain set of propositions. Probability is explained - as deducibility is - by a principle of truth-preserving under conditions of variability of terms. It is a triadic relation between two sets of propositions and some constitutive representations:

A proposition $[q]$ is probable with regard to a class $[P]$ of propositions and with regard to a variable constituent $[c]$ if a variation of $[c]$ generating only true propositions in $[P]$ generates not only true propositions in $[Q]$. (Bolzano 1837a $\S 161)$

Similarly, a proposition $[q]$ is deducible from $[P]$ with regard to $[c]$ if a variation of $[c]$ generating only true propositions in $[P]$ generates only true propositions in $[Q]$. With regard to the relation between deducibility and probability, we may say with Jan Berg that probability is a weaker case of deducibility, or with Joëlle Proust that deducibility is the ideal limit case of probability with value $1 .^{28}$ Evaluating the probability of potential grounds $[P]$ of $[q]$ and comparing it to the probability of $[q]$ requires a uniform reference set of propositions. In scientific work, for example, it is common practice to consider a stock of well-established tenets as unquestionable. Such a set can be used to "probabilize" the propositions to be examined, as well as the potential grounds $[P]$ that are considered to explain them. Against this background set, we evaluate whether a suggested candidate $[p]$ for grounding $[q]$ has or has not the strength of higher probability than $[q]$.

\footnotetext{
28 "To say that a proposition $\mathrm{P}$ is derivable from the set $\Gamma$ of propositions with respect to a sequence of ideas-as-such is tantamount to saying that the conditional proposition: if $\Gamma$ is true, then $\mathrm{P}$ is true, is universally valid with respect to the sequence in question - in other words, that the degree of validity of this conditional is 1 with respect to the sequence. It is near at hand, then, to consider weaker cases of derivability where the conditional has a lower degree of validity. In this way Bolzano is led to his notion of probability. [...] This notion of probability is the logical relation of an hypothesis to its evidential support. Hence, Bolzano's notion of probability has the formal properties of the concept of conditional probability" (Berg 2000, p. 54).

"Derivability [...] is an extreme case of the relationship of probability. [...] When the "comparative validity' of the proposition $M$ with respect to $A, B, C, D \ldots$ is less than 1, there is no longer any relationship of derivability, but a relationship of probability" (Proust 1989, p. 89).
} 
It is rare, however, that epistemic agents in the evaluation of their assertions unconditionally rely on a completely determined reference set of propositions. Even if the axioms of an axiomatic science or the dogmas of a fundamentalist religion provide models for absolute reference sets, scientists at least will admit that their first principles stand in certain dependence relations to propositions external to the system. Bolzano mentions such mutual dependencies between different domains of knowledge in the introduction to the Theory of science. Admitting dependence relations certainly does not entail a throwback to skepticism by way of relativism, but rather a "throwforth" to an open-mindedness that acknowledges "foundherent" relations beyond the limits of a certain domain. ${ }^{29}$ Keeping in mind that also the seemingly most basic truths involve a web of assumptions remedies the flaw of haughty dogmatism pretending to identify which truths are absolutely foundational grounds.

Even in cases of assumptions that are more reliable then the tested judgment we should weigh the costs of prolonging the investigation against the damage of error. Bolzano honestly admits that the rule of at least equal probability for grounding propositions is itself not an immediate judgment and, therefore, exposed to the "danger of error". This danger, however, is considered more minor than "being determined by any other rule or by mere accident" with respect to the judgments to be tested. ${ }^{30}$ Since neither doubt nor trust is subject to unconditional randomness, a remaining unavoidable possibility of error is not a good reason to reject a given truth (Bolzano 1837a $\$ 332.7$, annotation). This epistemic moral reflects an advice given by Kohelet according to which one should not become "overly righteous". 31 Being overly concerned with testing the ultimate possible reason for and especially against each judgment made would destroy one's epistemic health. ${ }^{32}$ It would be as insane as taking each apparently immediate judgment as being unquestionably truth-conforming.

As heuristic rule no. 7- "Consulting judgments of others and experience"suggests, an important factor for making proper decisions regarding the ways and length of explanatory investigation is the experience from shared epistemic practices. Under the concept of "common sense" (gemeiner Menschenverstand) Bolzano subsumes performances of consensus and common semiotic systems without specifying, however, whether the term "common" is to be understood in a distributive or in a collective sense. In the first case, "common sense" would refer to a general property of all human beings; that is, to the kind of understanding that all of them have due to their nature. In the second case, the term would refer to a property that human beings have together, to a kind of understanding that grows out of their practical and mental interactions. In view of some remarks and expressions-especially in

\footnotetext{
29 For the concept of "foundherency" see Haack (1993).

30 A rule inferior in this respect is the Cartesian rule of universal doubt (or its weaker version of universal testing), which is criticized for being impracticable. Since it is never possible to test all our judgments, we need a principle of selection in order to decide which judgments may remain untested. But exactly this principle is missing in the Cartesian rule of universal doubt.

31 "Don't be overly righteous, neither make yourself overly wise. Why should you destroy yourself?" (Bible: Kohelet 7, p. 16).

32 In his Von der weisen Selbsttäuschung (On Wise Self-Deception), Bolzano even praises deception and error as "sometimes useful [...] even for the most wise and virtuous of our species" (Bolzano 1976, p. 111).
} 
Bolzano 1837a $\$ 331-\mathrm{I}$ am inclined to favor the second interpretation, at least for some occurrences of the term "common sense". ${ }^{33}$ Collective epistemic properties imply not merely "social routes to knowledge" but also the shared intentionality of "collective epistemic agents". ${ }^{34}$ Collective epistemology takes epistemic agents to be "deliberators engaging in certain cognitive activities from a first person perspective" which "marks" the rational point of view. Since the first person perspective allows for singular and plural specification, the "locus of epistemic authority and responsibility" can be distributed "within and across" collectives. It is held that epistemic processes often have to be accounted for as processes of joint individual contributions. Reasons that become "salient from the group perspective" will then have "immediacy" for individuals, in function of their group membership. ${ }^{35}$

One manifestation of "common sense" is consensus, considered by Bolzano as "a particular indicator of a judgment's truth", especially when "the proposition itself is not doubted in spite of dissent about its ground" (Bolzano 1837a §315.6). The claim that a consensual assertion " $q$ !" indicates its truth-conformity is admittedly poignant in those cases where the reasons given for the assertion are not only different but conflicting. Cases of convergence in judgment in spite of diverging reasons seem to be paradigmatic for the need to search for the best explanation of the asserted truth. Insofar, reliance on consensus is not the mere "faith of optimists" or the contingent "fashion" of a "party spirit". 36 Accounting for Bolzanian knowing requires considering all the processes involved in infallibility evaluation. None of them can provide per $s e$ the ultimate warrant for infallibility. Epistemically virtuous agents will take consensus on $[q]$ not as a license for dogmatic insistence on their assertion's infallibility, but rather as a motive for increasing the search for grounds. Combining trust in the judgment's truth-conformity with virtues like prudence and curiosity in a balanced way creates the integrity warranting a successful search for the best explanation. Consensual trust in $[q]$ is an ideal starting point to engage in exploration and comparison of the most promising explanations of $[q] .{ }^{37}$

Similarly, shared semiotic systems are important tools in the task of evaluating infallibility. Bolzano holds that thoughts shaped in purely subjective ideas, that is, in mere "mentalese", are too ephemeral for objective tests of truth-conformity. Such testing requires us to get thoughts "into our grip", so that they can be recalled "as often as

\footnotetext{
33 For instance, Bolzano equates a judgment that "almost all human beings" avow "as with One mouth" with an "utterance of the common sense" (Bolzano 1837a §331.4).

34 Cf. Gilbert (2004); Tollefsen (2007).

35 Tollefsen (2007).

36 "Furthermore, even if all who investigate will converge on a given opinion, that does not make it true. [...] The conviction that convergence coincides with truth is the faith of optimists, not part of a proper definition of truth"; "[W]hen we form beliefs, we frequently rely on the consensus of others to guide us [...] In the $[\ldots]$ case, where agreement is used as evidence to settle belief, one is pursuing truth for oneself, and the agreement of others is simply taken as diagnostic of truth. Agreement, however, is not always diagnostic of truth" (Goldman 1999, pp. 12, 71).

37 Bolzano gives the example of the "doctrine of the imperishability of substances" that we can adopt with full confidence, even if all the reasons philosophers provide in order to prove it should be untenable. This truth is taken to be deeply rooted in human reason (Vernunft), since "even assuming a beginning one cannot think of an end of substances" (Bolzano 1838, p. 71f).
} 
we like". This purpose is achieved by the use of adequate signs whose function is "to apprehend thoughts that rushed through our soul and to subject them to more accurate testing” (Bolzano 1837a §344.13). Especially complex representations are dependent on adequate signs that serve as the "bonding agent" or "cement" of their elements (Bolzano 1837a §344.12; §334.3-5). Bolzano does not advance anything like a "private language argument", but the way he discusses a theory of signs (Bolzano 1837a $\S \S 334-344)$ as part of heuristics makes it clear that he considers a semiotic system to be essentially the result of inter-subjective endeavor. Although semiotic systems are conventional, they aim at avoiding arbitrariness and misunderstanding. They cash the mass of subjective representations into a currency that enables intra- and intersubjective trade with truth and explanation. One interest of such trade clearly lies in making thoughts available to objective testing. Other advantages of the use of signs are the possibility of longer inferential series, a better survey of epistemic processes and the chance of being led to new and unexpected thoughts by random assemblies of signs (Bolzano 1837a §334.6-8). All these functions play relevant roles in infallibility evaluation, although none of them can warrant infallibility in its own right.

\section{Conclusion}

Bolzanian knowing is introduced as a reflective attitude that epistemic agents take towards their own assertions. The "reflection" is supposed to reveal the assertion's value of infallibility. This evaluation involves explanatory attempts at "ascending" to potential grounds of the asserted truth. The endeavor of explaining asserted truths involves not only the rules of "inverted" methods, but also subjective decisions requiring a combination of skills and character traits. None of the rules mentioned can guarantee infallibility, and neither can skills nor virtuous character traits, nor any specific combination of these factors. It seems to follow then that Bolzanian heuristics annuls the possibility of Bolzanian knowing. We are doomed to accept that all reflective attitudes rest on the approximations of the "best possible" evaluation of an assertion's fallibility, and hence fall into the scope of Bolzanian believing.

We can accept this verdict with a shrug - after all, there seems to be nothing bad in assuming that reflective assessment of one's assertions is always striving for the "best possible" evaluation and that the "perfect" borderline case is just an ideal, a construct helping us to not lose sight of our goal. We can say, in this case, that Bolzanian knowing is accounted for by the following analysis:

(4) A knows $\mathrm{B}$ that $[q]$ iff A believes ${ }_{\mathrm{B}}$ that $[q]$ \& A's evaluation of her asserting $[q]$ as fallible reveals a high probability of $[q]$.

This analysis can be related to the claims of Bolzanian epistemic ethics that demand to call a proposition "secure" if its probability "for a certain being is very large and if there are circumstances which make it foolish or illicit to consider the possibility of the opposite" (Bolzano 1837b §317.3). In such circumstances—so we might claimthere is not only a right to call the asserted proposition "secure", but also a right to consider our attitude as "knowing".

Earlier in this paper, I suggested another option for dealing with the insufficiencies of infallibility evaluation that allows for a more substantial distinction of Bolzanian 
knowing from believing. To provide the value of the absolute to knowing, we might resort to the idea of a decisional "leap" that leaves probability considerations behind. Let us assume that the attitude of believing implies awareness of potential error, whereas the attitude of knowing is the result of a decision to set at nought such awareness. Knowing then appears as an attitude whose salient virtue is not trust but rather audaciousness. Instead of trusting in the truth-conformity of her fallible assertion, the knowing agent dares to state the infallibility of her assertion. Such an approach can be accounted for by the following analysis:

(5) A knows $_{\mathrm{B}}$ that $[q]$ iff A asserts $[q] \&$ A evaluates her asserting $[q] \&$ A audaciously decides that her evaluation reveals infallibility.

It is not clear how satisfactory such an analysis of knowledge can be. First, it allows two agents in identical epistemic situations with identical epistemic background to have different attitudes toward their assertion " $q$ !": While agent A believes that $[q]$ because her salient virtue is prudence, agent B knows that $[q]$ because her salient virtue is audaciousness. Second, there is the problem of virtues being gradual properties, turning into vices when they reach a certain degree or when they become dominant. Audaciousness is valuable not per se, but only in the appropriate situation and in an appropriate measure. It may be, however, that such a "decisional" conception of knowledge fits the purpose of settling the epistemic status of foundational principles in axiomatic systems. For the pragmatic purpose of working with such principles it is an advantage to attribute to them the status of being known to be the fundamentals. And it is an advantage to keep the sense of this "being known" stronger than that of "being believed". It is wise to keep in mind, however, that rash decisions to "leap" into knowledge might testify to vicious rather than virtuous audaciousness.

Acknowledgements This paper is dedicated to my teacher Kevin Mulligan. I would like to extend my gratitude to Arianna Betti, Marije Martijn and an anonymous referee for their insightful and constructive comments that helped me improve this paper.

\section{References}

Baier, A. (1992). Trusting people. Philosophical Perspectives, 6, 137-153.

Berg, J. (1976). Bolzanos Metaphysik. In G. Oberkofler \& E. Zlabinger (Eds.), Ost-West-Begegnung in Österreich: Festschrift für E. Winter (pp. 27-33). Wien: Böhlau.

Berg, J. (2000). From Bolzano's point of view. The Monist, 83, 47-67.

Bolzano, B. (1837a). Wissenschaftslehre. In L. Winter et al. (Eds.) (1969). Bernard Bolzano Gesamtausgabe. Reihe 1 (Vol. 11-14). Stuttgart-Bad Canstatt: Frommann Holzboog.

Bolzano, B. (1837b). Theory of science. Attempt at a detailed and in the main novel exposition of logic with constant attention to earlier authors. R. George (Transl. \& Ed.) (1972). Berkeley and Los Angeles: University of California Press.

Bolzano, B. (1837c). Theory of science. J. Berg (Transl. \& Ed.) (1973). Dordrecht/Boston: D. Reidel.

Bolzano, B. (1838). Athanasia oder Gründe für die Unsterblichkeit der Seele. Frankfurt a. M.: Minerva GmbH. (Unveränderter Nachdruck 1970.)

Bolzano, B. (1839). Von der mathematischen Lehrart. J. Berg (Ed.) (1981). Stuttgart - Bad Cannstatt: Fromann-Holzboog.

Bolzano, B. (1976). Ausgewählte Schriften. E. Winter (Ed.). Berlin: Union Verlag.

Carruthers, P. (2006). Simple heuristics meet massive modularity. In P. Carruthers, S. Laurence, \& S. Stich (Eds.), The innate mind. Culture and cognition (Vol. 2, pp. 181-198). Oxford: Oxford University Press. 
Chisholm, R. (1991). Bernard Bolzano's philosophy of mind. Philosophical Topics, 19, 205-214.

de Jong, W. R., \& Betti, A. (2008). The classical model of science: A millennia-old model of scientific rationality. Synthese. doi:10.1007/s11229-008-9417-4.

Gilbert, M. (2004). Collective epistemology. Episteme: A Journal of Social Epistemology, 1, 95-107.

Goldman, A. (1999). Knowledge in a social world. Oxford: Clarendon Press.

Greco, J. (2003). Knowledge as credit for true belief. In M. DePaul \& L. Zagzebski (Eds.), Intellectual virtue: Perspectives from ethics and epistemology (pp. 111-134). Oxford: Oxford University Press.

Haack, S. (1993). Evidence and inquiry: Towards reconstruction in epistemology. Oxford, Malden (MA): Blackwell.

Krause, A. (2004). Bolzanos Metaphysik. Freiburg/München: Karl Alber.

Lapointe, S. (2008). Bolzano, a priori knowledge and the Classical Model of Science. Synthese doi:10. 1007/s11229-008-9421-8.

Lehrer, K. (1997). Self-trust. A study of reason, knowledge, and autonomy. Oxford: Clarendon Press.

Proust, J. (1989). Questions of form. Logic and the analytic proposition from Kant to Carnap. Minneapolis: University of Minnesota Press.

Rescher, N. (2005). Epistemic logic. A survey of the logic of knowledge. Pittsburgh: University of Pittsburgh Press.

Sebestik, J. (1992). Logique et mathématique chez Bernard Bolzano. Paris: Vrin.

Swank, C. (2000). Epistemic vice. In G. Axtell (Ed.), Knowledge, belief, and character. Readings in virtue epistemology (pp. 195-204). Lanham/Boulder/NY/Oxford: Rowman \& Littlefield.

Tatzel, A. (2002). Bolzano's theory of ground and consequence. Notre Dame Journal of Symbolic Logic, 43, 1-25.

Tollefsen, D. (2007). Collective epistemic agency and the need for collective epistemology. In N. Psarros \& K. Schulte-Ostermann (Eds.), Facets of sociality (pp. 309-329). Frankfurt etc.: Ontos.

Zagzebski, L. (2000). From reliabilism to virtue epistemology. In G. Axtell (Ed.), Knowledge, belief, and character. Readings in virtue epistemology (pp. 113-122). Lanham/Boulder/NY/Oxford: Rowman \& Littlefield. 